УДК 159.922.4

Е. Л. Трофимова

Байкальский государственный университет, г. Иркутск, Российская Федерация

\title{
ПРЕДСТАВЛЕНИЯ СОВРЕМЕННЫХ СТУДЕНТОВ О РОЛИ ГРАЖДАНИНА
}

\begin{abstract}
АНнотАция. Гражданская идентичность как часть социальной идентичности может рассматриваться через призму таких индикаторов как: образ гражданина, репертуар ролевых позиций, посредством которых в обществе реализуется статус гражданина, установки по отношению к Родине, уровень гражданской активности. Активное формирование гражданских позиций происходит именно в юношеском возрасте, что обуславливает актуальность исследования на выборке студентов. В качестве респондентов были задействованы студенты Байкальского государственного университета и Иркутского регионального колледжа педагогического образования. В статье на основе как количественных, так и качественных методов представлены результаты эмпирического исследования представлений современных студентов о ролевых позициях гражданина, отношение к Отечеству и готовность реализовать гражданское поведение. Полученные данные позволяют сделать выводы о преобладание у студентов ситуативно-позитивного отношения к Родине, а также определить конструкты ролей: «Жиитель страны», «Сибиряк», «Законопослушный», «Избиратель», «Защитник», «Патриот», «Активист-общественник», «Пацифист» и «Предатель», через осуществление которых в обществе реализуется гражданское поведение человека.

кЛЮЧЕВЫЕ СЛОВА. Социальная идентичность; гражданская идентичность; конструкт; образ гражданина; отношение к Отечеству.

ИНФОРМАЦИЯ О СТАТЬЕ. Дата поступления 28 февраля 2017 г.; дата принятия к печати 20 марта 2017 г.; дата онлайн-размещения 31 марта 2017 г.
\end{abstract}

E. L. Trofimova

Baikal State University,

Irkutsk, Russian Federation

\section{PRESENT-DAY STUDENTS' VISIONS OF THE CITIZEN'S ROLE}

ABSTRACT. Civil identity as part of social identity can be viewed through the prism of such indicators as: citizen's image, repertoire of role positions, through which the society implements the status of citizen, attitudes towards the homeland, the level of civic engagement. Active formation of civil positions occurs exactly in the junior age, which determines the topicality of the investigation using a sample of students. As respondents, the students of Baikal University and Irkutsk Regional College of Pedagogical Education are involved. On the basis of quantitative and qualitative methods, the article presents the results of empirical investigation of ideas of the present-day students' visions of , the citizen' role positions, the attitude to the Motherland and the willingness to implement civil behavior. The data gained allow to make conclusions of students' prevalence of the situational and positive attitude to the Motherland, as well as to the constructs of the roles: "The Inhabitant of the country», "A Siberian», "The Law-abiding Person», "The Voter», "The Defender», "The Patriot», «The Public Activist», «The Pacifist» and «The Traitor», through which the person's civil behavior is implemented.

KEYWORDS. Social identity; civil identity; construct; image of citizen; attitude the Motherland.

ARTICLE INFO. Received February 28, 2017; accepted March 20, 2017; available online March 31, 2017.

Последние годы возрос интерес исследователей к проблематике социальной идентичности, например, анализируются этнические, этнорегиональные, религиоз-

(C) Е. Л. Трофимова, 2017

\section{Baikal Research Journal}


ные, профессиональные, корпоративные и другие идентичности. Политики, социологи отмечают, что наметились тенденции активизации идеологии объединения российского народа. В основе консолидации, прежде всего, лежит формирование у россиян гражданской идентичности, под которой понимается разновидность социальной идентичности, определяющая осознание своей принадлежности к гражданскому сообществу, объединенному в рамках государства. Авторы, в том числе Л. М. Дробижева обращает внимание на то, что в условиях возрастающей угрозы терроризма и экстремизма, ростом ксенофобий востребована гражданская идентичность, гражданское сознание и поведение $[1 ; 2]$. В отечественных и зарубежных исследованиях нет пока единой точки зрения относительно данного феномена, его структуры, соотношения с другими близкими в смысловом поле понятиями: государственная, российская, национальная, этническая, культурная идентичность.

Исследования, посвященные различным аспектам изучения гражданской идентичности, представлены в работах: Е. М. Арутюновой, Т. В. Водолажской, М. Н. Губогло, Л. М. Дробижевой, В. Н. Ефименко, А. Г. Здравомыслова, А. М. Кондакова, И. В. Коноды, А. А. Логиновой, Н. С. Попова, С. В. Рыжовой, Г. У. Солдатовой, М. Ф. Черныш, М. А. Юшина и др. [1-10]. Тем не менее, в отечественной социальной психологии проблематика гражданской идентификации остается еще недостаточно разработанной как в теоретическом, так и в практическом плане.

Н. Л. Иванова рассматривает социальную идентичность как «целостное динамическое образование, как систему ключевых социальных конструктов личности». Структуру представляет как единство когнитивных и ценностно-мотивационных особенностей личности [3].

А. Н. Татарко, Н. М. Лебедева, Т.А. Терехова считают, что гражданская идентичность является одним из компонентов социального капитала и имеет ведущее значение для экономического развития страны [11; 12]. В качестве основных характеристик идентичности А. Н. Татарко и Н. М. Лебедева называют определенность и валентность [13, с. 47].

В качестве структурных компонентов гражданской идентичности Т. В. Водолажской, например, выделяются: когнитивный, ценностный и эмоциональный компоненты [4]. По мнению А. А. Логиновой: когнитивный, ценностный и деятельностный. Содержание когнитивного компонента гражданской идентичности составляют «знания об идеальном гражданине, о гражданской общности, о государственной символике; знания об истории Отечества и его культурных традициях, о политических событиях, происходящих в государстве, о законах» и др. Содержание ценностного компонента гражданской идентичности образуют «ценности «Родина», «толерантность», «благородство», «великодушие», «ответственность», «долг», «гордость», «справедливость», «любовь к Отечеству, к гражданской общности»» и др. Содержание поведенческого компонента образуют «действия и поступки гражданского содержания: участие в гражданских акциях, митингах, социальных проектах, в субботниках по благоустройству города, соблюдение общественного порядка» и др. Функцией когнитивного компонента является «рефлексивно-оценочная функция, функциями ценностного компонента - мотивационная и регулирующая функции, поведенческого компонента - оценочная и ценностная» [5].

Следовательно, в обобщенную модель структуры гражданской идентичности входят следующие компоненты:

- когнитивный (знание о принадлежности к одной социальной общности);

- ценностно-смысловой (позитивное, негативное или двойственное отношение к принадлежности);

- эмоциональный (принятие или непринятие своей принадлежности);

- деятельностный (поведенческий - гражданская активность).

\section{Baikal Research Journal}


Таким образом, осознание гражданской идентичности предполагает принятие своей принадлежности к государству, возникновение чувства со-причастности к проблемам страны и ответственности за происходящее и будущее малой и большой Родины. Мы рассматриваем гражданскую идентичность как совокупность следующих характеристик: представления о ролевых позициях, посредством которых в обществе реализуется статус гражданина, отношение к Отечеству и готовность реализовать гражданское поведение.

Студенческий возраст - это наиболее сензитивный период для формирования мировоззрения, определения своих жизненных позиций. Современное поколение студентов выросло уже в другом государственном пространстве, на иных идеалах и ценностях, на иных культурно-символических элементах. Происходящие в стране и мире социальные изменения за последние десятилетия привели к переосмыслению ценностей, к отказу от сложившихся традиционных установок, естественно, это осложняет формирование идентичностей.

Целью нашего исследования стало выявление характеристик гражданской идентичности: представлений современных студентов о ролевых позициях, посредством которых в обществе реализуется статус гражданина, отношение к Отечеству и готовность реализовать гражданское поведение.

Исследование проводилось на протяжении последних лет в несколько этапов:

- на базе Байкальского государственного университета г. Иркутска, приняли участие студенты разных факультетов, в количестве 137 человек, возраст от 17 до 23 лет;

- на базе Иркутского регионального колледжа педагогического образования, 309 студентов из 18 групп ${ }^{1}$.

Все респонденты русской национальности (так как студентов других национальностей оказалось незначительно, мы исключили их ответы из выборки).

В качестве методов исследования применялись:

- метод свободных ассоциаций;

- метод репертуарных решеток Келли;

- тест М. Куна, Т. Макпартленда «Кто я?»;

- опросник И. В. Кулешовой, П. В. Степанова, Д. В. Григорьева (шкала отношение к Отечеству);

- анкетирование.

В тесте М. Куна, Т. Макпартленда «Кто я?» нас интересовали позиции связанные с гражданской идентичностью. В ответах 41,61 \% респондентов были варианты, указывающие на значимость гражданской идентичности. На позициях от 1 до 10 стояли такие определения себя как: граждан(-ин, -ка) РФ 24,82 \%; патриот (ка) 6,57 \% ; ЖЖитель Иркутска, Иркутской области 6,57 \%; будущее нашей страны $1,46 \%$; противник действующей власти $1,46 \%$; налогоплательщик $0,73 \%$; избиратель $0,73 \%$. В целом, личностные характеристики доминируют над гражданскими, территориальными и национальными. Полученные данные свидетельствует о недостаточно высоком уровне сформированности гражданской самоидентификации у студентов.

Одним из этапов исследования гражданской идентичности стало конструирование ролевых типологий, связанных с реализацией гражданской активности. Согласно ролевой теории, изменение поведения происходит в результате принятия ролей, которые детерминируются предписаниями социальных систем, групповыми нормами, ролевыми ожиданиями [14]. Следовательно, необходимо выяснить, посредством репертуара каких ролевых позиций, в представлениях современных

${ }^{1}$ Исследование проводилось преподавателем колледжа, студенткой магистратуры по направлению «Психология» С. Н. Клевитовой.

\section{Baikal Research Journal}


студентов осуществляется гражданская идентификация. Студентам было предложено подобрать ассоциации к словам-стимулам: гражданин, гражданская идентичность, ответить на вопрос: «Гражданин - он какой?», продолжить предложения: «Я чувствую себя гражданином своей страны, когда...», «Моя принадлежность к гражданам России проявляется в том, что...».

Семантическая обработка полученной информации (учитывались негативная - положительная оценка и повторяемость схожих по смыслу слов) позволила выделить следующие ролевые позиции:

1. Защитник.

2. Предатель.

3. Жиитель страны.

4. Сибиряк.

5. Законопослушный.

6. Избиратель.

7. Патриот.

8. Активист-общественник.

9. Пацифист (выступающий против насилия, войн, терроризма во всем мире, миротворец).

Далее мы обратились к методу репертуарных решеток Келли. С целью выявления конструктов применялся метод минимального контекста. Респонденту предъявлялись ролевые элементы из ролевого списка, которые составлялись таким образом, что вероятность появления всех ролевых элементов была одинакова: это позволяет избежать выборочного давления на выявление личностных конструктов респондента. Респонденту предлагалось зафиксировать какое-либо важное качество, по которому двое из обозначенных лиц сходны между собой и, следовательно, отличны от третьего. Далее необходимо назвать, в чем конкретно состоит отличие третьего персонажа от 2 других. Ответы на эти вопросы составляют 2 полюса конструкта: А - сходство, В - различие. После заполнения указанным образом первой строки респондент может переходить ко второй, где ему предлагается следующая пара или триада. Полученный массив конструктов обрабатывался с помощью контент-анализа и интерпретировался в соответствии с выделенными семантическими единицами. Оценка каждого ролевого персонажа осуществлялась по шкале от -10 до +10 по качествам, выделенным респондентом.

Мы выбрали те качества, которые наиболее часто повторялись у респондентов и таким образом получили конструкты выделенных выше ролевых позиций. На рис. 1 представлен портрет ролевого персонажа «Защитник».

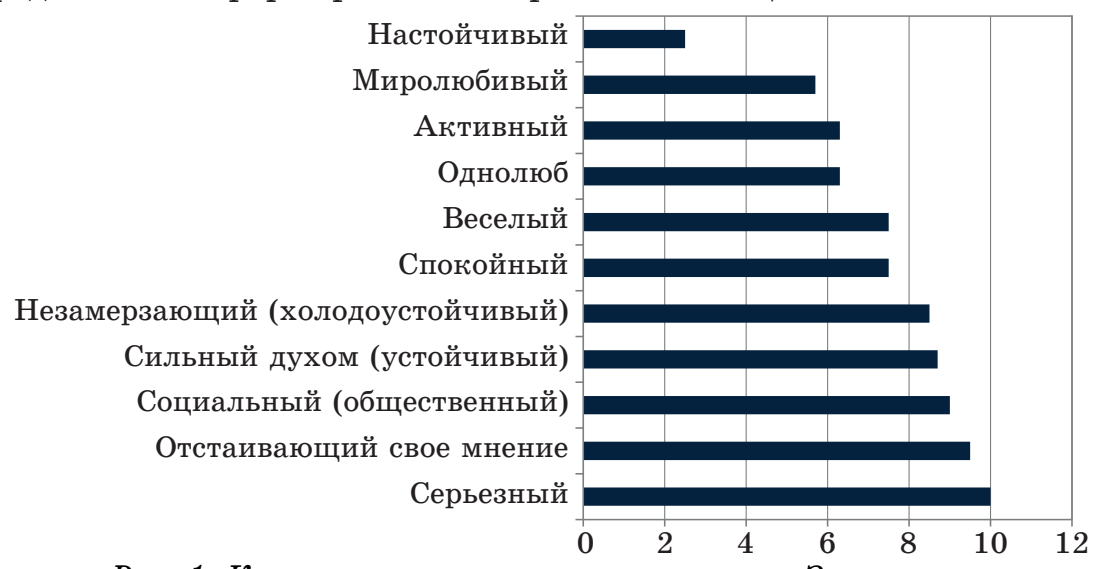

Рис. 1. Конструкты ролевого персонажа «Защитник»

\section{Baikal Research Journal}


Как мы видим, образ имеет только положительную окраску, главное качество, которое может характеризовать защитника - «серьезный» и наиболее высоко оценены социально значимые характеристики, появление конструкта «незамерзающий" связано с ассоциацией с солдатом, военным, который готов переносить любые тяготы, в том числе холод, защищая Родину. В описании «Защитника» также встречаются конструкты: «свой», «родной».

Семантическое ядро характеристики «Жћитель страны» составили качества: «веселый (жизнерадостный)» $(9,3)$, «сильный духом (устойчивый)» $(8)$, «смелый, мужественный», «общественный», «настойчивый», «честный». Основным конструктом персонажа «Сибиряк» оказалось «закаленный» (10), а также появилось негативно окрашенной качество «трусливый» (10), но интерпретировалось оно студентами ближе к значению «тревожный»: боится перемен, кризиса, потери работы, переживает за детей, что вполне естественно является отражением переживаний, связанных с экономическим кризисом. Кроме того, «Сибиряк»: «сильный духом», «настойчивый», «устойчивый», «мужественный», «серьезный», скорее «уверенный», «спокойный» и «скромный», «умный». Образ «Сибиряк», как мы видим, отличается наибольшей дифференцированностью и сложностью, в нем присутствуют конструкты, отражающие как эмоциональное отношение, так и социально-психологические, морально-нравственные и интеллектуальные качества.

Наиболее высоко оцениваемым качеством позиции «Законопослушный» являются конструкты: «спокойный» $(9,5)$ и «отстаивающий свое мнение» $(9,5)$, ниже оценены: «социальный $(8,5)$, «серьезный» $(8,5)$, «устойчивый» $(8,3)$, «уверенный» $(8)$, «мужественный» $(7,75)$. Также опрошенные студенты считают, что «Законопослушный» «грустный / недовольный», «скучный», встречаются «нетолерантный» и «неинтересный», т. е. при общей позитивности персонажа, эмоциональная окраска преобладает скорее отрицательная.

Ролевой персонаж «Избиратель» прежде всего, характеризуется как «общественный» (10), «сильный духом (устойчивый)» $(9)$, «мужественный» $(8,75)$, «серьезный» $(8,5)$, «уверенный» $(8)$, «отстаивающий свое мнение» $(8)$, «настойчивый» (7), «честный» (7). Таким образом, более выражены социально-психологические качества.

Более значимым качеством, по мнению респондентов, для позиций «Патриот» и "Активист-общественник» также является идеаторный конструкт «общественный/социальный» (средняя оценка 10 баллов). Кроме того, «Патриот» воспринимается как: «серьезный» $(10)$, «отстаивающий свое мнение» $(9,5)$, «спокойный» $(9,5)$ и «активный» $(8,5)$, в ответах студентов встречаются конструкты «родной», «небезразличный», «справедливый», «надежный», но одновременно «скучный», «грустный».

Характеристика «Предатель», единственная позиция выступающая антонимом роли гражданина, имеет расширенное семантическое ядро, состоящее как из положительно, так и отрицательно окрашенных качеств (рис. 2). Только для этой позиции выявлена высокая оценка интеллектуального конструкта, что интерпретировалось как необходимость стратегического планирования, проявления хитрости, изворотливости.

Также студенты присваивали данной роли качества: «чужой», «эгоистичный», «несправедливый».

Наиболее противоречивым оказался портрет ролевого персонажа «Пацифист», по мнению респондентов, характеризуется одновременно и мужественным, и трусливым, веселым, и грустным, и настойчивым и податливым. Конструируя данный образ студентам сложно было представить какого-то конкретного человека как данного ролевого персонажа.

\section{Baikal Research Journal}




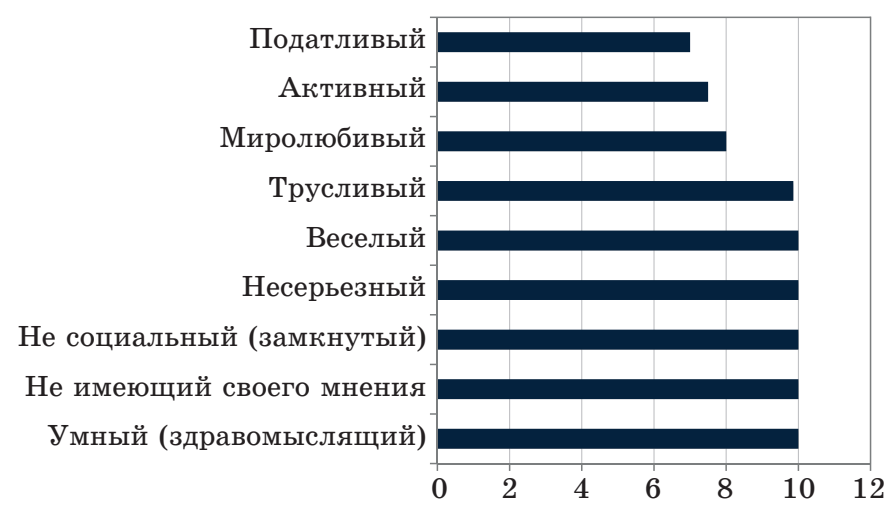

Рис. 2. Конструкты ролевого персонажа «Предатель»

Анализ полученных данных позволил нам выделить конструкты, характеризующие образ гражданина (наиболее часто повторяющиеся и более высоко оцениваемые в описании разных ролевых позиций) в представлениях студентов. Результаты последующей оценки гражданина по выделенным конструктам показаны на рис. 3.

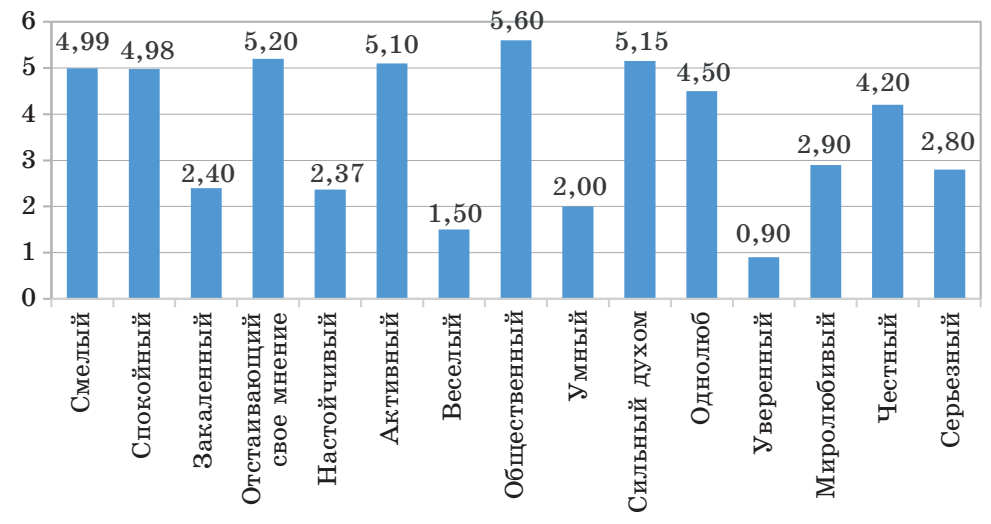

Рис. 3. Образ гражданина в представлениях студентов

Как мы видим, основными качествами гражданина являются следующие: «общественный», «отстаивающий свое мнение», «сильный духом», «активный», «смелый», «спокойный», «однолюб», «честный». Корреляционный анализ показал, что наблюдаются значимые связи между конструктами образа (табл.).

Значимые корреляционные связи между конструктами "образа гражданина"

\begin{tabular}{|l|c|c|c|c|c|}
\hline $\begin{array}{l}\text { Конструкты образа } \\
\text { гражданина }\end{array}$ & Активный & $\begin{array}{c}\text { Общественный } \\
\text { (социальный) }\end{array}$ & Умный & $\begin{array}{c}\text { Сильный } \\
\text { духом }\end{array}$ & Миролюбивый \\
\hline Смелый & $\begin{array}{c}r=0,340, \\
\mathrm{p}=0,022\end{array}$ & $\begin{array}{c}r=0,237, \\
\mathrm{p}=0,049\end{array}$ & $\begin{array}{c}r=0,300, \\
\mathrm{p}=0,020\end{array}$ & $\begin{array}{c}r=0,255, \\
\mathrm{p}=0,050\end{array}$ & - \\
\hline Спокойный & $\begin{array}{c}r=-0,272, \\
\mathrm{p}=0,036\end{array}$ & - & - & - & $\begin{array}{c}r=0,235, \\
\mathrm{p}=0,050\end{array}$ \\
\hline $\begin{array}{l}\text { Отстаивающий свое } \\
\text { мнение }\end{array}$ & - & - & $\begin{array}{c}r=0,236, \\
\mathrm{p}=0,019\end{array}$ & - & - \\
\hline Однолюб & - & - & - & $\begin{array}{c}r=0,537, \\
\mathrm{p}=0,0001\end{array}$ & - \\
\hline Честный & - & - & - & $\begin{array}{c}r=0,299, \\
\mathrm{p}=0,040\end{array}$ & - \\
\hline
\end{tabular}

\section{Baikal Research Journal}


Полученные значимые корреляции позволяют сформулировать следующую обобщенную характеристику гражданина: «общественный / социальный», «смелый», «сильный духом», «отстаивающий свое мнение», «честный», «однолюб» по отношению к своей Родине, «миролюбивый», но скорее «спокойный» и не очень «умный» .

Изучая отношение к Отечеству, как компонент гражданской идентичности, мы применяли опросник И. В. Кулешовой, П. В. Степанова, Д. В. Григорьева. Авторы обращают внимание на то, что отношения бывают ценностными (позитивными), неценностными (равнодушными) и антиценностными (негативными).

$19,4 \%$ из принимавших участие в исследовании студентов продемонстрировали устойчиво-позитивное отношение, то есть для них характерны высокий уровень гражданственности и патриотизма. Они чувствуют свою личную ответственность за судьбу страны, хотели бы жить и работать в своей стране, гордятся Родиной и готовы ее защищать при необходимости. При этом подобные чувства вызваны не конъюнктурой, не модой на патриотизм, а являются глубоко личными, пережитыми.

$56 \%$ опрошенных студентов обнаружили ситуативно-позитивное отношение к Родине. Родина для них - это скорее родной дом, место, где они родились и живут. По их мнению, то, что происходит в стране и на их «малой родине», имеет между собой мало общего. Они сопереживают событиям, происходящим в стране, но высокой гражданской активности не проявляют.

$24 \%$ респондентов имеют ситуативно-негативное отношение к Отечеству. Для них присущи в большей степени нейтральные (равнодушные) оценки. Хотя в соответствующей ситуации они могут давать и «патриотично» окрашенные ответы. Но, в целом, то, что происходит со страной и с ними самими, имеет между собой мало общего.

И 0,6 \% студентов считают, что Родина - это просто место, где они живут, и которое легко можно поменять на любое другое. Они не считают себя чем-то обязанными стране, не ощущают значимости национальных праздников, не видят для себя перспектив в этой стране.

В исследовании студентам вузов г. Иркутска, мы задавали вопрос: «Патриотизм, любовь к Родине для Вас это?» [15; 16]. Ответы распределились следующим образом: $55,2 \%$ считают, что это чувство сопричастности с родной землей, $31,5 \%$ хотя и идеологическая, но все же личностно значимая категория, $9,3 \%-$ ничего не значащее, абстрактное понятие, 4 \% - не смогли определиться с ответом.

Студентом предлагалось также ответить на вопрос «Считаете ли Вы себя патриотом?» Как оказалось, к патриотам себя относят 74,5 \% опрошенных; не считают себя патриотами $19 \%$ респондентов, 6,5\% - затруднились с ответом. Результаты достаточно оптимистичны, однако, мы склонны считать, что велика вероятность мотивированного искажения ответов. Так на уровне деятельностного компонента, полную готовность защищать Родину в случае угрозы и жить в своей стране продемонстрировали около 31 \% студентов педагогического колледжа. Среди студентов вуза однозначно уезжать за пределы России не хотели бы $44,53 \%$, а 7,3 \% наоборот видят свое будущее только в другой стране; $14 \%$ студентов совсем не интересуются событиями общественно-политической жизни и около $34 \%$ - не реализуют свои права избирателя.

Таким образом, полученные результаты позволяют сделать следующие выводы:

1. В представлениях современных студентов гражданская идентификация осуществляется посредством репертуара следующих ролевых позиций: «Жиитель страны», «Сибиряк» (территориальные), «Законопослушный», «Избиратель» (социально-правовые), «Защитник», «Патриот» (социально-политические), «Акти-

\section{Baikal Research Journal}

электронный научный журнал Байкальского государственного университета 
вист-общественник», «Пацифист» (нравственные) и «Предатель» как позиция выступающая антонимом роли гражданина.

2. Конструкты обозначенных ролевых позиций в основном состоят из положительных качеств. Наиболее дифференцированным и сложным является образ «Сибиряк», как наиболее близкий студентам, в нем присутствуют эмоциональные, социально-психологические, морально-нравственные и интеллектуальные конструкты. Ролевые персонажи «Законопослушный» и «Патриот» при общей позитивности образа одновременно характеризуются качествами «скучный», «грустный», «неинтересный». Таким образом, выполнение этих позиций, как и роли «Избиратель» осознается как значимое, необходимое, но не вызывает ярко окрашенных положительных эмоций. Персонаж «Защитник» имеет только положительную окраску, отличающие его конструкты - «серьезный» и «незамерзающий». Только для позиции «Предатель» выявлена высокая оценка интеллектуального конструкта, но преобладают в описании образа отрицательные качества.

3. Усредненная характеристика гражданина, в представлениях студентов, состоит из следующих конструктов: «общественный / социальный», «смелый», «веселый», «сильный духом», «отстаивающий свое мнение», «честный», «однолюб» по отношению к своей Родине, «миролюбивый», но скорее «спокойный» и не очень «умный».

4. У большинства студентов преобладает ситуативно-позитивное отношение к Родине. Однако, если на декларативном уровне большая часть студентов демонстрируют сформированность гражданской идентичности, то деятельностный компонент выражен значительно слабее. Студенты продемонстрировали низкую информированность о культуре, обычаях, традициях народов страны и региона; низкий уровень консолидации на уровне региона; невысокую социально-политическую активность.

5. В образовательном пространстве актуальным остается поиск средств, форм работы, позволяющих формировать высокий уровень гражданской идентичности и адекватных представлений о реализации роли гражданина.

\section{Список использованной литературы}

1. Дробижева Л. М. Государственная и этническая идентичность: выбор и подвижность / Л. М. Дробижева // Гражданская, этническая и религиозные идентичности в современной России / отв. ред. В. С. Магун. - М. : Ин-т социологии РАН, 2006. - С. 10-30.

2. Дробижева Л. М. Государственно-гражданская идентичность и межэтническое согласие: теоретические и социально-практические проблемы / Л. М. Дробижева // Власть. 2014. - № 11. - C. 12-17.

3. Иванова Н. Л. Изменения этнической и гражданской идентичности в новых общественных условиях / Н. Л. Иванова, Г. Б. Мазилова // Вопросы психологи. - 2008. № 2 . - С. $83-93$.

4. Водоложская Т. В. Идентичность гражданская / Т. В. Водоложская // Образовательная политика. - 2010. - № 5/6. - С. 140-142.

5. Логинова А. А. Формирование гражданской идентичности школьников средствами интернет проектов : автореф. дис. ... канд. пед. наук : 13.00.01 / А. А. Логинова. - Самаpa, 2010. $-23 \mathrm{c}$.

6. Ефименко В. Н. Структурные компоненты и содержательное наполнение понятия «гражданская идентичность / В. Н. Ефименко // Теория и практика общественного развития. - 2013. - № 11. - С. 250-254.

7. Иванишенко Н. Н. Социальная ответственность и гражданская активность молодежи / Н. Н. Иванишенко // Социология. - 2007. - № 3/4. - С. 22-34.

8. Хомяков М. Б. Идентичность, толерантность и идея гражданства / М. Б. Хомяков // Гражданская, этническая и религиозные идентичности в современной России / под ред. Л. М. Дробижевой. - М. : Ин-т социологии РАН, 2006. - С. 30-57.

\section{Baikal Research Journal}


9. Чернов В. В. Формирование гражданственности молодежи / В. В. Чернов // Социология. - 2008. - № 2. - С. 216-221.

10. Юшин М. А. Политические механизмы формирования гражданской идентичности молодежи в современной России : автореф. дис. ... канд. полит. наук : 23.00.02/ М. А. Юшин. - Тула, 2007. - 24 с.

11. Терехова Т. А. Метаанализ взаимосвязи инновационного потенциала и социального капитала личности / Т. А. Терехова // Социальные и гуманитарные науки на Дальнем Востоке. - 2012. - № 3 (26). - C. 38-44.

12. Терехова Т. А. Научно-педагогические традиции и инновации кафедры социальной и экономической психологии / Т. А. Терехова, Е. Л. Трофимова // Известия Иркутской государственной экономической академии. - 2015. - T. 25, № 2. - С. 330-335. - DOI: 10.17150/1993-3541.2015.25(2).330-335.

13. Татарко А. Н. Социальный капитал: теория и психологические исследования : монография / А. Н. Татарко, Н. М. Лебедева. - М. : Рос. ун-т дружбы народов, 2009. — 233 с.

14. Вяткин А. П. Личное конструирование как механизм экономической социализации в транзитивном обществе / А. П. Вяткин // Известия Иркутской государственной экономической академии. - 2015. - T. 25, № 5. - C. 897-903. — DOI: 10.17150/19933541.2015.25(5).897-903.

15. Карнышев А. Д. Межэтническое взаимодействие и межкультурная компетентность / А. Д. Карнышев, М. А. Винокуров, Е. Л. Трофимова. - Иркутск : Изд-во БГУЭП, 2009. - $310 \mathrm{c}$.

16. Трофимова Е. Л. Формирование готовности к межкультурному сотрудничеству у студентов в процессе обучения и воспитания в вузе / Е. Л. Трофимова // Сибирский психологический журнал. - 2013. - № 47. - С. 129-140.

\section{References}

1. Drobizheva L. M. Civil and ethnic identity: choice and mobility. In Magun V. S. (ed.). Grazhdanskaya, etnicheskaya $i$ religioznye identichnosti $v$ sovremennoi Rossii [Civil, ethnical and religious identities in today's Russia]. Moscow, Sociology Institute of RAS Publ., 2006, pp. 10-30. (In Russian).

2. Drobizheva L. M. State and civil identity and interethnic accord: theoretical and practical social problem. Vlast' = The Power, 2014, no. 11, pp. 12-17. (In Russian).

3. Ivanova N. L., Mazilova G. B. Changes of ethnic and civil identities in new social terms. Voprosy psikhologii = Issues of Psychology, 2008, no. 2, pp. 83-93. (In Russian).

4. Vodolozhskaya T. V. Civil identity. Obrazovatel'naya politika = Journal of Educational Policy, 2010, no. 5/6, pp. 140-142. (In Russian).

5. Loginova A. A. Formirovanie grazhdanskoi identichnosti shkol'nikov sredstvami internet proektov. Avtoref. Kand. Diss. [Formation of pupils' civil identity through Internet project means. Cand. Diss. Thesis]. Samara, 2010. 23 p.

6. Efimenko V. N. Structural components and content of the civil identity concept. Teoriya $i$ praktika obshchestvennogo razvitiya = Theory and Practice of Social Development, 2013, no. 11, pp. 250-254. (In Russian).

7. Ivanishenko N. N. Social responsibility and youth's civil activeness. Sotsiologiya $=$ Sociology, 2007, no. 3/4, pp. 22-34. (In Russian).

8. Khomyakov M. B. Identity, tolerance and idea of citizenship. In Drobizheva L. M. (ed.). Grazhdanskaya, etnicheskaya $i$ religioznye identichnosti $v$ sovremennoi Rossii [Civil, ethnical and religious identities in today's Russia]. Moscow, Sociology Institute of RAS Publ., 2006, pp. 30-57. (In Russian).

9. Chernov V. V. Formation of youth's civic spirit. Sotsiologiya = Sociology, 2008, no. 2, pp. 216-221. (In Russian).

10. Yushin M. A. Politicheskie mekhanizmy formirovaniya grazhdanskoi identichnosti molodezhi v sovremennoi Rossii. Avtoref. Kand. Diss. [Political mechanisms of forming youth's civil identity in today's Russia. Cand. Diss. Thesis]. Tula, 2007. 24 p.

11. Terekhova T. A. Meta-analysis of interrelation between personality's innovation potential and social capital. Sotsial'nye i gumanitarnye nauki na Dal'nem Vostoke = The Humanities and Social Studies in the Far East, 2012, no. 3 (26), pp. 38-44. (In Russian).

\section{Baikal Research Journal}


12. Terekhova T. A., Trofimova E. L. Scientific and pedagogical traditions and innovations of Social and Economic Psychology Chair. Izvestiya Irkutskoi gosudarstvennoi ekonomicheskiy akademii = Bulletin of Irkutsk State Academy of Economics, 2015, vol. 25, no. 2, pp. 330-335. DOI: 10.17150/1993-3541.2015.25(2).330-335. (In Russian).

13. Tatarko A. N., Lebedeva N. M. Sotsialnyi kapital: teoriya i psikhologicheskie issledovaniya [Social Capital: Theory and Psychological Research]. Moscow, People's Friendship University of Russia Publ., 2009. 233 p.

14. Vyatkin A. P. Private construction as a mechanism of economic socialization in transitive society. Izvestiya Irkutskoi gosudarstvennoi ekonomicheskoi akademii = Bulletin of Irkutsk State Economics Academy, 2015, vol. 25, no. 5, pp. 897-903. DOI: 10.17150/19933541.2015.25(5).897-903. (In Russian).

15. Karnyshev A. D., Vinokurov M. A., Trofimova E. L. Mezhetnicheskoe vzaimodeistvie i mezhkul'turnaya kompetentnost' [Inter-ethnic interaction and intercultural competence]. Irkutsk, Baikal State University of Economics and Law Publ., 2009. 310 p.

16. Trofimova E. L. Formation of students' readiness for cross-cultural cooperation in the course of training and education in university. Sibirskii psikhologicheskii zhurnal = Siberian Psychological Journal, 2013, no. 47, pp. 129-140. (In Russian).

\section{Информация об авторе}

Трофилова Елена Леонидовна - кандидат психологических наук, доцент, кафедра социальной и экономической психологии, социологии и социальной работы, Байкальский государственный университет, 664003, г. Иркутск, ул. Ленина, 11, e-mail: trofimova-bgy@mail.ru.

Author

Elena L. Trofimova - PhD in Psychology, Associate Professor, Chair of Social and Economic Psychology, Sociology and Social Work, Baikal State University, 11 Lenin St., 664003, Irkutsk, Russian Federation; e-mail: trofimova-bgy@mail.ru.

\section{Библиографическое описание статьи}

Трофимова Е. Л. Представления современных студентов о роли гражданина / Е. Л. Трофимова // Baikal Research Journal. - 2017. — T. 8, № 1. — DOI: 10.17150/24116262.2017.8(1).27.

\section{Reference to article}

Trofimova E. L. Present-day students' visions of the citizen's role. Baikal Research Journal, 2017, vol. 8, no. 1. DOI: 10.17150/2411-6262.2017.8(1).27. (In Russian).

\section{Baikal Research Journal}

